\title{
An analysis of methods to achieve robustness towards a lean product development process
}

\author{
Alan Cabello, Karina Flores, Myrna Flores, Muhammad Khan, Ahmed Al-Ashaab \\ EPFL, Lausanne, Switzerland, \{alan.cabello,karina.flores,myrna.flores\}@epfl.ch \\ Cranfield University,UK, \{muhammad.khan,a.al-ashaab\}@cranfield.ac.uk
}

\begin{abstract}
Since Taguchi's introduction to robustness much has been researched about it, particularly into the field of new product development. Despite the attention given to the subject by academia, recent research has found that industry has yet to fully grasp its benefits. Among the main attributed factors, lie the complexity of the proposed statistical tools and a general misconception of the concept and its implementation. Based on Toyota's Product Development System, the term Conceptual Robustness is broadly defined based on three forms of variation: physical, design and market. Parting from the this definition and as part of the LeanPPD Project, the objective of this paper's contribution is threefold: 1), to present the state of the art on research in the area of robustness, 2) propose a taxonomy in order to understand the different scopes of available resources and 3) finally identifying the possibilities to achieve conceptual robustness (that of Sobek et al., 1999) with the available resources presented to the industry by academic research.
\end{abstract}

\section{Key Words}

Robust, Conceptual Robustness, Lean, New Product Development, Set Based Concurrent Engineering, Taguchi, Variation

\section{Introduction}

New Product Development (NPD) has for long been in the eye of scholars, engineers and managers as the key to success in today's competitive markets. Yet the question remains: how to make successful, dynamic and versatile new products that cope with the current market? Among the extensive studies and propositions to address the challenge, Lean Thinking has been regarded with promise. Since its origins in Japanese industrial culture and its success in manufacturing, much has been said and done to take this philosophy onto other areas of business. Within the frame of the European Union's $7^{\text {th }}$ Framework, the LeanPPD project seeks to propose a model that will take NPD closer towards Lean Thinking. Taking Toyota's Lean Product Development System as a model, Ward et al. (1995) advocate that set-based concurrent engineering (SBCE) is potentially the underlying cause for the company's continuous success. SBCE has been defined (Kahn et al., 2011) as a process in which a multifunctional design team [Concurrent Engineering] reasons, develops and communicates about sets of solutions in parallel [Set-Based Engineering]. As the design progresses, they gradually narrow their respective sets of solutions based on the knowledge gained. As they narrow, they commit to staying within the sets so that others can rely on their communication. In 1999 Sobek et al. presented a detailed study on Toyota's Lean Product Development System, highlighting the role of SBCE in the company's process and the underlying framework to achieve it. In order to achieve SBCE Sobek et al (1999) proposed a series of principles. To "seek Conceptual Robustness" is among these principles. Which Sobek et al. (1999) broadly defined as being based on three forms of variation: physical, design and market. To the authors' knowledge, no further research expanded on this definition and while the term robustness has been frequently coined, it still appears to be generally misunderstood.

Addressing the needs of European manufacturing companies for a new model that extends beyond lean manufacturing, and incorporates lean thinking in the product design development process, the LeanPPD project has developed a SBCE model based on the main principles 
identified in the literature (Kahn et al., 2011). The model defines the stages and activities that represent the product development process to be employed in the LeanPPD (lean product and process development) project. Seeking to develop a set of tools and practices for its implementation, this research parts from the work of Sobek et al. (1999) as a first step to better define and understand Conceptual Robustness, identify the state of the art in the literature and identify which available methods can be used to achieve it.

\section{Research Objective}

In order for an organization to understand Conceptual Robustness and apply it within its NPD, it must commence by understanding the concept, generating the necessary knowledge on the available methods and acquire an overview of its applicability with in its own structure. The research objective of this paper is to identify and classify the available literature on robustness and identify which available methods can be used to achieve conceptual robustness for a lean product development process, considering all types of variation (physical, design and market).

This study, within the frame of the European Union's 7th Framework LeanPPD Project and as part of the LeanPPD Model currently under development, will present its recommendation of methods to implement for conceptual robustness based on the perceived strengths and shortcomings of each method. Companies will be able to select the method that correlates best with their NPD process.

\section{Conceptual Robustness: Its definition and practical implementation}

As stated by Cabrera-Rios et al. (2002), the Taguchi Method is the conventional approach to achieve robustness. This term has been defined as the insensitivity to sources of unwanted variation or noise factors (Hasenkamp et al, 2008). Taguchi defines noise factors as potential sources of variation that cannot be controlled by the designer. Noise factor is a term popularized by Taguchi within Parameter Design, of which the objective is to select the optimum levels for the controllable system parameters, so that a product is functional (Dean, 1991). Examples of noise factors are temperature, ageing or manufacturing variation. There has been a particular emphasis on the development of statistical techniques aimed at immunizing product and process development from sources of variation or noise factors, respectively (see e.g. Hunter, 1985; Box and Jones, 1992; and Arvidson, Kammerlind et al., 2001), of which we refer to in this paper as Micro Methods.

Sobek et al. (1999) expanded on Taguchi's concepts and suggested to "Seek Conceptual Robustness", defining robustness in a broader sense as: to offer stability in three forms of variation in product development: physical, design and market. Emphasizing on robustness as a means to shorten significantly development times and the ease of future developments. Followed by briefly describing the three forms of variation:

- Physical variation is depicted as that popularized by Taguchi, in which designs are functional with disregard to material wear, manufacturing variations or even weather changes.

- Design variation goes in hand with the flexibility of concepts within the design team. This means creating designs that work well regardless of what the rest of the team decides to do.

- Market variation refers to design susceptibility to changes in demand or competition. Therefore robustness can be generated by applying strategies to decrease this susceptibility, such as shorter development cycles, manufacturing flexibility and standardization. A design that can consider future changes in customer requirements or that can be sold to the clients in a short period of time will be less susceptible to market variation. 
While the concept appears straightforward, further analysis shows that grasping robustness with the available literature is still complex. At a first instance and as stated before, the term Robustness brings us directly to Taguchi. Yet we soon realize the Taguchi Method only offers a set of statistical tools to approach robust design, the primary tools for the Taguchi Method being Orthogonal Arrays and the signal-to-noise $(\mathrm{S} / \mathrm{N})$ ratio. The former substantially reduces the number of required experiments and the latter simultaneously finds the most robust combination and the best possible performance (Taguchi and Clausing, 1990). Therefore, not considering the full scope of Conceptual Robustness. Table 1 presents some key definitions found in the literature for Robustness.

\begin{tabular}{|l|l|}
\hline \multicolumn{1}{|c|}{ Definition } & \multicolumn{1}{|c|}{ Author } \\
\hline "Robustness means insensitivity to variation." & Box and Fung, 1994 \\
\hline $\begin{array}{l}\text { "Robustness is the potential for success under varying circumstances or } \\
\text { scenarios." }\end{array}$ & Bettis and Hitt, 1995 \\
\hline $\begin{array}{l}\text { "Conceptual Robustness: The idea that members of a team can make } \\
\text { simultaneous, interdependent decisions by treating their uncertainty about } \\
\text { others' decisions as a kind of noise..." }\end{array}$ & $\begin{array}{l}\text { Chang \& Ward, } \\
1995\end{array}$ \\
\hline $\begin{array}{l}\text { "The state where the technology, product, or process performance is minimally } \\
\text { sensitive to factors causing variability (either in manufacturing or user's } \\
\text { environment) and aging at the lowest manufacturing cost." }\end{array}$ & Taguchi et al., 2000 \\
$\begin{array}{l}\text { "Robustness can be defined as designing a product in such a way that the level } \\
\text { of its performance at various customer usage conditions is same as that at the } \\
\text { nominal conditions." }\end{array}$ & Jugulum, 2009 \\
\hline
\end{tabular}

Table 1 - Definitions in the literature for Robustness

To expand on this unclear definition, this research conducted an extensive literature review resulting in a very few methods aimed at Conceptual Robustness, lesser still considering Sobek et al.'s (1999) three forms of variation. It was found that with the introduction of Taguchi methods (Taguchi \& Clausing, 1990; Phadke, 1989) much of the focus in the literature on handling uncertainty in engineering has been shifted towards the principles of Robust Design. Yet due to the lack of a precise definition of robustness, the principles of Robust Design have been often used to denote very different meanings and encompass very different attributes (McManus \& Hastings, 2005). The focus of research concerning robust design has been the development of techniques, or statistical tools. Comparatively little attention has been given to framing these techniques into a method (Arvidsson et al., 2007). Furthermore and possibly given the intricacy of the subject, robust design in itself as conceived by Taguchi has still not been widely adopted within industry (Arvidsson et al., 2003; Gremyr and Hasenkamp, 2011).

Analysis showed that few methods are available to support Conceptual Robustness although they might not all expressly do so. Individually analyzed, each of these methods provides a viable structure to achieve some level of Conceptual Robustness in NPD. Nevertheless, apart from their unanimous view on top management support, each one proposes a different structure, various statistical, marketing and/or design tools, variable principles and practices, unique examples and particular concepts. This leads to a complex comparison on an already misunderstood field.

Research by Gremyr et al. (2003) give a clear example of how scarce is the knowledge on the subject in the industry, despite the large amount of related academic research. There is indeed a need to bridge the gap between principles and tools, so that engineers and managers understand the purpose and have an overall view of the tools they are using towards Conceptual Robustness. Besides the work by Arvidsson, Gremyr and Hasenkamp (2007), which mainly focuses on robust design and not Conceptual Robustness, little has been done in the literature to help clarify these concepts. This research attempts to do so in the following classification. 


\section{Proposed Methods Classification: Micro/Macro Methods}

As a first instance, it is important to realize that not all available methods address the same needs. A different scope involves a varied level of opportunities and these must be categorized by the size of the effort involved. Therefore methods may have been designed specifically on one level and/or applied within a Macro or a Micro level or both.

At a Macro level the opportunities involve the design and development of an entirely new product or service, or the major redesign of an existing one. Organizations must develop or reorganize their NPD process based on a new or different model. This involves training the management team on how to resource and guide the effort and using a structured approach to the application of the principles and tools at a Micro level. According to Mader (2002), a Micro method has a smaller scope than the Macro method and is likely to pertain to the execution of a subtask within a Macro method. Micro methods are specific technical tools that will aid in the sub levels of the design process.

At the Macro level, there is not always a consistent standard for integrating a method into the existent NPD process, given that NPD processes are varied depending on the product or service they generate. Management training is of great importance, as their support and knowledge is key to the success of the methods implementation and in most cases, to the success of NPD (Mader, 2002). Generally, once the management team is fully trained, engaged and the appropriate project has been selected, training at a Micro level may begin. Technical training is centered on the actual project level and the subtasks in the design process. It is at the Micro level that diverse mathematical and statistical tools may be applied to the selection of characteristics in a design. Figure 1 illustrates a graphical view of the integration of Micro and Macro Methods in an organization in the Product Development Process.

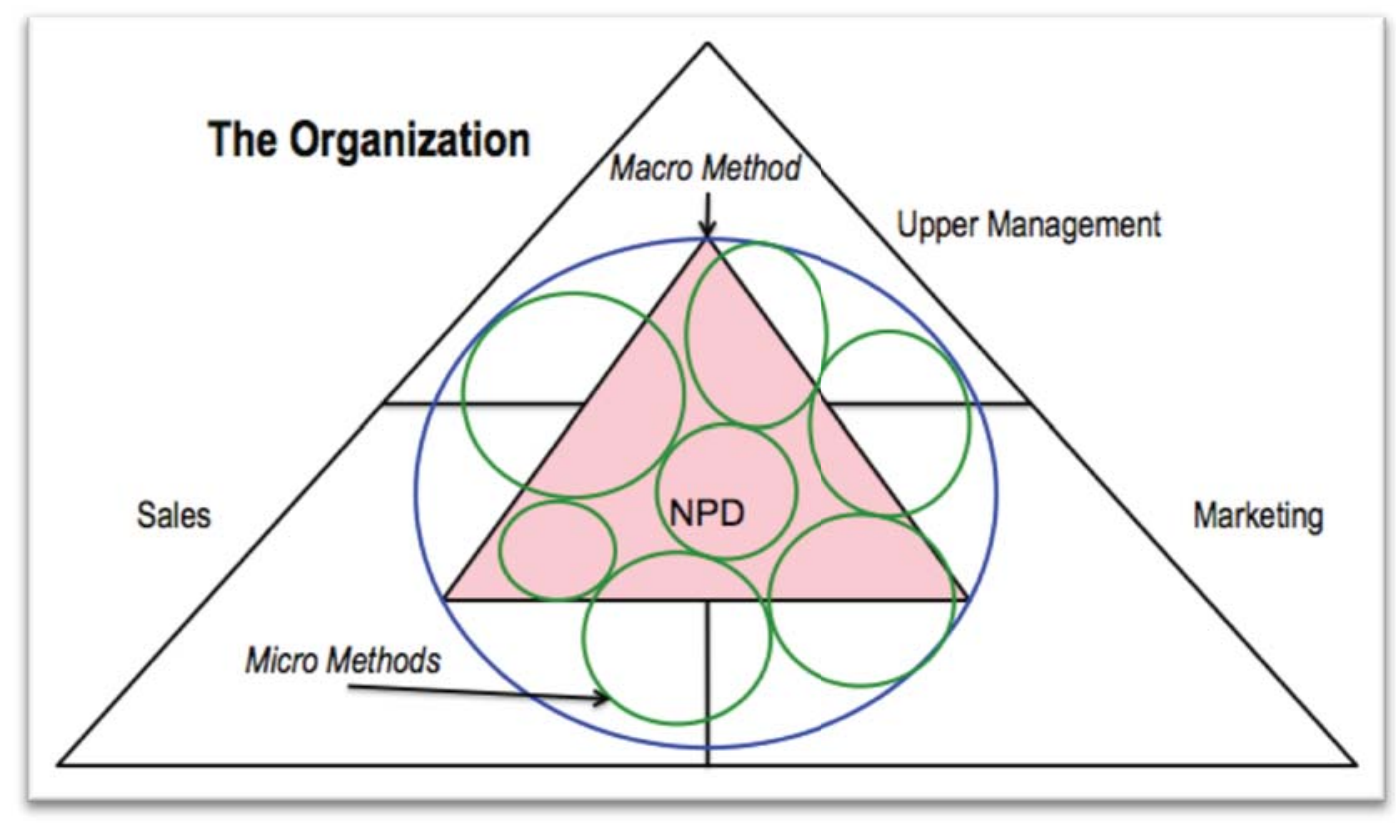

Figure 1 - Robustness Method Classification According to their Scope in an Organization

While seeking for Conceptual Robustness one cannot consider only a method at the Micro level, given that it will only address the aspects of a design based on certain requirements or characteristics. It is the origin and development of these characteristics that in some cases may address the three forms of variation stated by Sobek et al. (1999) as necessary for Conceptual Robustness. This classification (Macro/Micro Method) allows an organization a greater range of possibilities to chose from and adapt to their current process. As an example, an organization 
may choose to apply Design For Six Sigma (Tennant, 2002) as their solution to Conceptual Robustness, while using one or all of Taguchi's methods for a robust design. The following sections present a short summary of the main available Micro and Macro Methods for Robust Design or Conceptual Robustness.

\section{Micro Methods}

\subsection{Axiomatic Design}

Axiomatic Design is a principle-based design method focused on the concept of domains that seeks to reduce the complexity of the design process. The primary goal of axiomatic design is to establish a systematic foundation for design activity a set of implementation methods and two axioms: The Independence Axiom, to maintain the independence of functional requirements and the Information Axiom that provides a means of evaluating the quality of designs, thus facilitating a selection among available design alternatives (Suh, 1990).

\subsection{QFD - Quality Function Deployment}

Akao (1972) proposed a "method to transform user demands into design quality, to deploy the functions forming quality, and to deploy methods for achieving the design quality into subsystems and component parts, and ultimately to specific elements of the manufacturing process." QFD helps transform customer needs into engineering characteristics for a product or service, prioritizing each product or service characteristic while simultaneously setting development targets.

\subsection{FMEA - Failure Mode and Effect Analysis}

Johansson et al. (2006) describe a method for variation reduction that is applicable in the concept selection phase as well as in improving existing designs. They call the method failure mode and effects analysis (FMEA) and maintain that it is useful for identifying noise factors that influence a design.

\subsection{Taguchi Method}

Taguchi and $\mathrm{Wu}$ (1979) advocate the use of orthogonal arrays where both control factors and noise factors are varied. These experiments are analyzed by the use of signal-to-noise ratios to identify robust designs. The rationale behind the signal-to-noise ratios is that they are linked to the quadratic loss function. Overall, the Taguchi method emphasizes pushing quality back to the design stage, seeking to design a product/process which is insensitive or robust to causes of quality problems.

\subsection{DoE - Design of Experiments}

Design of Experiments (DoE) refers to experimental methods used to quantify indeterminate measurements of factors and interactions between factors statistically through observance of forced changes made methodically as directed by mathematically systematic tables. Kackar (1985) and Hunter (1985) further developed Taguchi's ideas on the use of DoE.

\subsection{Smart Assemblies}

Smart assemblies (Downey et al., 2003) is an approach to robust design which can be used when other methods are not sufficient. A smart assembly has features, not otherwise required by the function of the design, which allow the design to absorb or cancel out the effects of variation. A passive smart assembly absorbs variation once during the assembly process, and then is fixed. An active smart assembly automatically adapts to variation as it occurs throughout the lifetime of the assembly. 


\subsection{Other Statistical Micro Methods}

Nigam and Turner (1995) present a review of statistically based methods for studying how variation caused by different noise factors propagates to the total variation. This study includes: Linear stackup, or root-sum-squares method (RSS), Croft's method, Extended Taylor series approximation, Hasofer-Lind index method, Approximation by numerical integration or quadrature technique and Monte Carlo simulation.

While the use and positive results of these Micro Methods have been reported in multiple cases throughout the literature, their complex mathematical functions present their largest downside. Therefore software has been developed to facilitate the methods implementation through simulations, as is the case of CAD software that is widely available in the market (i.e. SolidWorks, AutoCad, CATIA, etc.).

\section{Macro Methods}

\subsection{DFSS - Design for Six Sigma}

DFSS consists of a set of needs-gathering, engineering and statistical methods to be used during product development. Engineering determines the physics and technology to be used for the product's functions; DFSS ensures that those functions meet the customer's need and that the chosen technology will perform those functions in a robust manner throughout the product's life (Hu et al., 2004). Companies such as Hewlett-Packard and Motorola have used DFSS.

\subsection{MOGA - Multi-objective Genetic Algorithm}

MOGA (Luo et al., 2005) provides a means to determine how variations in product performance and consumer preferences can be incorporated in the generation and comparison of design alternatives. Applying a multi-objective genetic algorithm incorporates multifunction criteria in order to identify better designs while incorporating the robustness criteria in the selection process. This method was developed through research involving cross-functional teams of Black \& Decker Corporation and the University of Maryland.

\subsection{DFV - Design for Variety}

DFV (Martin \& Ishi; 1996, 1997, 2002) is a series of structured methodologies to help design teams reduce the impact of variety on the life-cycle costs of a product. By using the Generational Variety Index (GVI) as an indicator of the amount of redesign required for a component to meet the future market requirements. The Coupling Index (CI) indicates the strength of coupling between the components in a product. The stronger the coupling, the more likely a change in one will require a change in the other. Companies such as Sony, Nortel Networks and InFocus have used concepts and details of DFV.

\subsection{VRM - Variation Risk Management}

VRM (Thornton et al., 2000) is the process of continually identifying, assessing, and mitigating variation risk. The VRM framework is supported by 22 industry practices. A practice is a set of methods that can be used to address one portion of the variation problem. A practice can also include supporting methods such as management support. For each practice, four levels of implementation maturity were identified. This model allows industry to assess their level of implementation and benchmark their processes against other industries. Companies such as Boeing, Xerox, ITT and Ford have used concepts and details of VRM.

\subsection{RDM - Robust Design Methodology}

While not a method in itself but a set of principles and practices, it must be acknowledged 
given its important contribution to the literature. RDM can be summarized as systematic efforts to achieve insensitivity to noise factors. These efforts are founded on an awareness of variation and can be applied in all stages of product design (Arvidsson, M., Gremyr, I. and Hasenkamp, T., 2007). According this definition, three principles of RDM were established: Insensitivity to noise factors, awareness of variation and continuous applicability. Each principle is implemented through a set of practices that are in turn supported by a wide variety of tools. According to the previously mentioned authors $17 \%$ of Swedish manufacturing companies apply RDM.

\section{Discussion}

Having presented a short summary of the main available Micro and Macro Methods, Table 2 presents the Macro methods analyzed and classified in this research in function of their capabilities to achieve Conceptual Robustness as defined by Sobek et al. (1999). A full circle has been used when that particular type of variation is considered, a half circle when that particular type of variation is not considered yet the authors consider it to be plausible, and an empty circle when no reference in the literature was found. It is important to note that this classification has been done only taking into account references found in the literature.

\begin{tabular}{|c|c|c|c|c|}
\hline $\begin{array}{l}\text { Macro } \\
\text { Method }\end{array}$ & $\begin{array}{l}\text { Consideration of } \\
\text { Physical Variation }\end{array}$ & $\begin{array}{c}\text { Consideration of Design } \\
\text { Variation }\end{array}$ & $\begin{array}{l}\text { Consideration of } \\
\text { Market Variation }\end{array}$ & $\begin{array}{c}\text { Micro Methods } \\
\text { used }\end{array}$ \\
\hline DFSS & $\begin{array}{l}\text { Through its } \\
\text { Optimization phase, it } \\
\text { may utilize one or } \\
\text { more statistical tools } \\
\text { such as Taguchi's to } \\
\text { ensure stability } \\
\text { towards variation. }\end{array}$ & $\begin{array}{l}\text { During its Identify and } \\
\text { Characterize phase, it } \\
\text { ensures a clear } \\
\text { understanding of } \\
\text { requirements that allow } \\
\text { flexibility of concepts. }\end{array}$ & $\begin{array}{l}\text { Although DFSS ensures } \\
\text { that functions meet the } \\
\text { customer's needs, DFSS } \\
\text { in itself does not } \\
\text { consider shifts in market } \\
\text { demand or competition. }\end{array}$ & $\begin{array}{l}\text {-Transfer } \\
\text { Function } \\
\text {-Taguchi } \\
\text { Methods } \\
\text {-EQFD } \\
\text {-FMEA }\end{array}$ \\
\hline MOGA & $\begin{array}{l}\text { It considers and defines } \\
\text { the functional design of a } \\
\text { product based on the } \\
\text { physical parameters of } \\
\text { the components selected } \\
\text { through simulations. }\end{array}$ & $\begin{array}{l}\text { Focuses mainly on the } \\
\text { product performance } \\
\text { variations (physical). }\end{array}$ & $\begin{array}{l}\text { This approach considers } \\
\text { the variations in customer } \\
\text { preferences due to } \\
\text { variations in usage } \\
\text { situations and conditions. }\end{array}$ & $\begin{array}{l}\text {-System Dynamic } \\
\text { Modeling } \\
\text {-Conjoint } \\
\text { Analysis } \\
\text {-Multi Object } \\
\text { Genetic } \\
\text { Algorithm }\end{array}$ \\
\hline VRM & $\begin{array}{l}\text { It utilizes one or more } \\
\text { statistical tools such as } \\
\text { Taguchi's to ensure } \\
\text { stability towards physical } \\
\text { variation. }\end{array}$ & $\begin{array}{l}\text { By determining the Key } \\
\text { Components early in the } \\
\text { process these are not likely } \\
\text { to be affected by variation } \\
\text { generated by each designer. }\end{array}$ & $\begin{array}{l}\text { It presents a series of } \\
\text { practices focused on } \\
\text { market variations as Risk } \\
\text { Assessment and the use of } \\
\text { FMEA. }\end{array}$ & \begin{tabular}{|l|}
-Taguchi \\
-Montecarlo \\
-RSS \\
-Tolerance Chain \\
Analysis \\
-FMEA
\end{tabular} \\
\hline DFV & $\begin{array}{l}\text { Using a modified version } \\
\text { of QFD, DFV revises the } \\
\text { physical properties of } \\
\text { every component in a } \\
\text { design. }\end{array}$ & $\begin{array}{l}\text { Through increased } \\
\text { "'headroom', of } \\
\text { specifications, designing a } \\
\text { component that may absorb } \\
\text { large change before } \\
\text { requiring redesign. }\end{array}$ & $\begin{array}{l}\text { DFV develops a product } \\
\text { architecture that allows } \\
\text { building on and further } \\
\text { developing the design, } \\
\text { according to changes in } \\
\text { customer/market needs. }\end{array}$ & $\begin{array}{l}\text {-Anova } \\
\text {-QFD }\end{array}$ \\
\hline
\end{tabular}

Table 2 - Method comparison to achieve Conceptual Robustness based on literature review. 
DFSS has been greatly successful since its origins in manufacturing. Yet with practicality also come certain shortcomings, as among others its ability to cope with market variation as defined by Sobek et al. (1999). Keeping in mind Conceptual Robustness is a practice supporting SBCE, although DFSS works through Concurrent Engineering, no reference in the literature was found related to DFSS support of Set Based Engineering.

Luo et al. (2005) propose through MOGA a means to determine how variations in product performance and consumer preferences can be incorporated in the generation and comparison of design alternatives. Despite presenting a solid example of the method's applicability through the design of a power tool, MOGA fails to consider design variation as of the design working well regardless of any changes made by the rest of the product development team.

Thornton (2000) proposes VRM, as a method to incorporate in a product development process. According to Thornton, VRM can serve as an overall framework for reducing variation from system design to production, having the benefit of being useful to apply to new or old product development projects. VRM as several other Macro Methods utilizes a mix of different methods and tools. The method has been utilized and validated through a number of companies in the US. Nevertheless, Padgalskas (2007) finds that it appears difficult to introduce its use among developers. As well, VRM only utilizes Concurrent Engineering early on to discuss and finalize Key Components, yet has no reference towards Set Based Engineering.

Although in itself not a method towards Conceptual Robustness, RDM presents through its practices a link between the principles of robustness and the wide array of available tools. Among the related research Gremyr and Hassenkamp in 2010 published a case study: Robust Design Methodology in practice, analyzing the use of tools for robustness in the Swedish industry. They concluded that companies have still not grasped, nor realized the full potential of robustness nor fully adopted the use of any of the tools that have been proposed in the literature. Therefore emphasizing on the importance of appropriate principles and practices' implementation, which then may be supported by the already wide-scope of tools.

\section{Conclusions and Future Work}

This paper's contribution is threefold, to present the state of the art on research in the area of robustness, propose a an overall view of current research in which the classification of methods in micro and macro methods aids the reader to understand the different scopes of available resources and finally identifying the possibilities to achieve conceptual robustness (that of Sobek et al., 1999) with the available resources presented to the industry by academic research. To propose a single method to achieve Conceptual Robustness within the NPD process proves difficult given varied organizational needs and the lack of methods that can take into account all types of variation: physical, design and market. Unless just recently formed, each company or organization has developed its own method or process for product development. Therefore a work culture has already been formed and most likely one or several tools have been implemented, successfully or not. Choosing the most appropriate method for conceptual robustness in product development will depend on these, as among other factors. Nevertheless, DFV does consider all types of variation that can affect the design and supports the implementation of Conceptual Robustness within a SBCE product development process. As well, the value of this method has been demonstrated through their practical application. Yet managers must keep in mind that methods are organizational tools, which will be useless without developer's proper understanding and upper management's full support.

This research is a first step to better define and understand Conceptual Robustness, establish the state of the art in the literature, propose a classification and identify which available methods can be used to achieve it. Future work includes encompasses the key elements that 
have been identified in the available literature into a series of steps for achieving Conceptual Robustness in product development. As a third step, a future case study will allow these steps to be tested, validated and integrated into the LeanPPD Model.

\section{Acknowledgments}

The authors thank the European Commission for supporting the LeanPPD project (NMP-FP7-214090) and the participating organizations for their collaboration, without which this research would have not been possible.

\section{References}

Arvidsson, M., Gremyr, I. and Hasenkamp, T. (2007) An Operationalization of Robust Design Methodology. Linköping University Electronic Press, Linköpings universitet

Bettis, R.A. and Hitt, M. (1995). The New Competitive Landscape. Strategic Management Journal 16:7-19 (Special Issue).

Box, G.E.P. and Fung, C.A., 1994. Quality quandaries - is your robust design procedure robust? Quality Engineering, 6 (3), 503-514.

Cabrera-Rios, M., Mount-Campbell, C.A., Irani, S.A., 2002. An approach to the design of a manufacturing cell under economic considerations. International Journal of Production Economics 78, 223-237.

Chang, Tzyy-Shuh, Ward, Allen C., Lee, Jinkoo, Jacox, Edwin H., (1994). Conceptual Robustness in Simultaneous Engineering: An Extension of Taguchi's Parameter Design. Research in Engineering Design 6:211222. Springer-Vertag London Limited

Dean, B. E., 1991. Taguchi approach to design optimization for quality and cost: an overview, Conference Paper: Annual Conference of the International Society of Parametric Analysts.

Downey, K., Parkinson, A., and Chase, K., 2003. An introduction to smart assemblies for robust design. Research in Engineering Design, 14 (4), 236-246.

Gremyr, I., M. Arvidsson, et al. (2003). "Robust Design Methodology: Status in the Swedish Manufacturing Industry", Quality and Reliability Engineering International, Vol 19 No (4), pp. 285-293.

Gremyr, I., Hasenkamp, T., (2011). "Practices of robust design methodology in practice." The TQM Journal, Vol. 23, No. 1, pp. 47-58. Emerald Group Publishing Limited

Gremyr, I., Johansson, P., (2005). "Robust design methodology - experiences among users in industry", Working Paper

Hasenkamp, T., Arvidsson, M., Gremyr, I., (2008), A review of practices for robust design methodology, Journal of Engineering Design, Vol. 20, No. 6

Hunter JS. Statistical design applied to product design. Journal of Quality Technology 1985; 17:210-221.

Johansson, P., et al., (2006). Variation mode and effect analysis: a practical tool for quality improvement. Quality and Reliability Engineering International, 22 (8), 865-876.

Kackar RN. (1985) Off-line quality control, parameter design, and the Taguchi method. Journal of Quality Technology; 17:176-188.

Khan, M., Al-Ashaab, A., Doultsinou, A., Shehab, E., Ewers, P., Sulowski, R., Frey, D.D., (2011) Set-Based Concurrent Engineering process within the LeanPPD environment. In Editors (Fukuda, S., Rock, G.) Improving Complex Systems Today (p. 433-440). Advanced Concurrent Engineering, Springer London

Mader DP (SigmaPro Inc.). DFSS and your current design process. Quality Progress 2002; 36(7):88--89.

Martin, M., \& Ishii, K. 1996!. Design for variety: A methodology for understanding the costs of product proliferation. ASME Design Engineering Technology Conf., Paper No. 96-DETC0DTM-1610.

Martin, M.V., \& Ishii, K. 1997!. Design for variety: Development of complexity indices and design charts. Proc. ASME Design Engineering Technology Conf., Paper No. DETC970DFM-4359.

Martin, M.V., \& Ishii, K. 2002!. Design for variety: Developing standardized and modularized product platform architectures. Research in Engineering Design 13(4), 213-235.

Nigam SD, Turner JU. Review of statistical approaches to tolerance analysis. Computer-Aided Design 1995; 27:6-15.

McManus, H.L. and Hastings, D.E. A framework for understanding uncertainty and its mitigation and exploitation in complex systems. In Fifteenth Annual International Symposium of the INCOS, Rochester, NY, 2005.

Padgalskas, N. (2007). Implementing Variation Risk Management During Product Development. Master Thesis. 
Massachusetts Institute of Technology.

Phadke MS. Quality Engineering using Robust Design. Prentice-Hall: Englewood Cliffs, NJ, 1989.

Robinson, T. J., C. M. Borror, et al. (2003). "Robust Parameter Design: A Review", Quality and Reliability Engineering International, Vol 20 No (1), pp. 81-101.

Sobek DK II; Ward AC; Liker JK, (1999) Toyota's Principles of Set-Based Concurrent Engineering. Sloan Management Review; Winter 1999; 40, 2; ABI/INFORM Global pg. 67

Suh, N.P., 1990. The principles of design. NewYork: Oxford University Press.

Taguchi, G. and Clausing, D. 1990. "Robust Quality", Harvard Business Review, vol. 68 (Jan.-Feb.), pp. 65-75.

Taguchi G, Chowdhury S, Taguchi S. Robust Engineering-Learn How to Boost Quality While Reducing Costs and Time to Market. McGraw-Hill: New York, 2000.

Taguchi G, Wu Y. Introduction to Off-Line Quality Control. Central Japan Quality Control Association: Nagoya, Japan, 1979.

Tennant, G., 2002. Design for Six Sigma: launching new products and services without failure. Hampshire: Gower Publishing Limited.

Thornton AC, Donelly S, Ertan B. More than just robust design: Why product development organizations still contend with variation and its impact on quality. Research in Engineering Design 2000; 12:127-143.

Ward, A.C., Liker, J. K., Cristiano, J. J. and Sobek, D. K. (1995), "The second Toyota paradox: How delaying decisions can make better cars faster", Sloan management review, vol. 36, pp. 43-43 
2012-06-18

\title{
An analysis of methods to achieve robustness towards a lean product development process
}

\section{Cabello, Alan}

Institute of Electrical and Electronics Engineers

\author{
Alan Cabello, Karina Flores, Myrna Flores, Muhammad Khan, Ahmed Al-Ashaab. An analysis of \\ methods to achieve robustness towards a lean product development process. 2012 18th \\ International ICE Conference on Engineering, Technology and Innovation (ICE 2012), 18-20 \\ June 2014, Munich, Germany. \\ http://dx.doi.org/10.1109/ICE.2012.6297672 \\ Downloaded from Cranfield Library Services E-Repository
}

